\title{
0 lugar das práticas curriculares diante do avanço da lógica privada sobre 0 setor público: 0 Emiti em Santa Catarina
}

\author{
The place of curriculum practices before the advance of private logic on the public sector: \\ the Emiti in Santa Catarina
}

\section{El lugar de las prácticas curriculares ante el avance de la lógica privada sobre el sector público: el Emitien Santa Catarina}

\author{
Berenice Rocha Zabbot Garcia* \\ Jane Mery Richter Voigt*
}

\section{Resumo}

Fatores políticos e, principalmente, econômicos têm afetado as políticas educacionais, influenciando o funcionamento dos sistemas de ensino, que numa visão utilitarista e economicista vêm promovendo um avanço da lógica privada sobre o setor público. A questão de pesquisa a ser abordada centra-se no que representa a adoção de uma proposta educacional advinda de uma instituição privada no contexto da educação pública. O presente artigo tem como objetivo discutir o lugar das práticas curriculares dos professores no Ensino Médio Integral em Tempo Integral (Emiti), considerando a parceria da Secretaria de Educação do Estado de Santa Catarina com o Instituto Ayrton Senna (IAS). A pesquisa, de abordagem qualitativa, foi desenvolvida por meio de entrevistas com professores de uma escola de Ensino Médio da rede pública do referido estado. O referencial teórico contempla os estudos curriculares no que tange às políticas e às práticas. A discussão está pautada na percepção desses docentes a respeito das suas práticas curriculares diante da proposta do IAS. Os resultados apontam para as dificuldades na adaptação da infraestrutura para viabilização de propostas que não reconhecem as realidades locais e para a restrição da autonomia curricular dos professores.

Palavras-chave: Políticas educacionais. Práticas curriculares. Ensino integral em tempo integral. Parceria públicoprivada.

Recebido em 19/05/2019 - Aprovado em 26/09/2019

http://dx.doi.org/10.5335/rep.v27i1.10578

Doutora em Educação - Psicologia da Educação, pela Pontifícia Universidade Católica de São Paulo (PUC-SP, Brasil). É professora titular da Universidade da Região de Joinville (Univille, Brasil). ORCID https://orcid.org/0000-0002-03534310. E-mail: berenice.rocha@univille.br

** Doutora em Educação - Psicologia da Educação, pela Pontifícia Universidade Católica de São Paulo (PUC-SP, Brasil). Atualmente é professora titular da Universidade da Região de Joinville (Univille, Brasil). ORCID https://orcid.org/00000003-2180-5476. E-mail: jane.mery@univille.br 


\section{Abstract}

Political and, mainly, economical factors have been affecting educational policies, influencing the functioning of education systems, which in a utilitarian and economist point of view has promoted an advance of private logic over the public sector. The issue to be addressed focuses on the meaning of the adoption of an educational proposal from a private institution in the context of public education. This article aims to discuss the place of teachers' curricular practices in integral High School- Full Time High School (Emiti), considering the partnership of Santa Catarina State Department of Education with the Ayrton Senna Institute. The research, with a qualitative approach, was developed through interviews with teachers of a public high school in the state. The theoretical framework contemplates curriculum studies, in terms of policies and practices. The discussion is based on the perception of these teachers about their curricular practices regarding the proposal of the Ayrton Senna Institute. The results indicate difficulties in adapting the infrastructure to enable proposals that do not recognize local realitiesand to restriction of the curricular autonomy of the teachers.

Keywords: Educational policies. Curriculum practices. Integral full time education. Public-private partnership.

\section{Resumen}

Los factores políticos y principalmente econômicos, han afectado a las políticas educativas, influyendo en el funcionamiento de los sistemas educativos, que desde una perspectiva utilitaria y economista han promovido un avance de la lógica privada sobre el sector público. La pregunta de investigación que debe abordarse se centra en la adopción de una propuesta educativa de una institución privada en el contexto de la educación pública. Este artículo tiene como objetivo discutir el lugar de las prácticas curriculares de los maestros en la escuela secundaria a tiempo completo (Emiti), considerando la asociación del Departamento de Educación del Estado (Provincia del Brazil) de Santa Catarina con el Instituto Ayrton Senna (IAS). La investigación, con un enfoque cualitativo, se desarrolló a través de entrevistas con maestros de una escuela secundaria provincial. El marco teórico incluye estudios curriculares sobre políticas y prácticas. La discusión se basa en la percepción de estos maestros con respecto a sus prácticas curriculares en vista de la propuesta de IAS. Los resultados apuntan a las dificultades para adaptar a la infraestructura para permitir propuestas que no reconocen las realidades locales y a la restricción de la autonomía curricular de los docentes.

Palabras clave: Políticas educativas. Prácticas curriculares. Enseñanza Integral. Escuelas de tiempo completo. Asociación público-privada.

\section{Introdução}

A reforma do Ensino Médio, proposta pela Lei n. 13.415/2017, introduz modificações na organização do currículo do Ensino Médio, como a introdução de itinerários formativos e da formação técnica profissional de nível médio de forma mais abrangente do que nas políticas anteriores. Além disso, essa lei também fomenta a implementação de escolas de ensino médio em tempo integral.

Em meio a esse cenário, o estado de Santa Catarina aderiu ao programa de Fomento à Implementação de Escolas em Tempo Integral, instituído pela Portaria MEC n. 1.145, de 10 de outubro de 2016 (BRASIL, 2016). Esse programa transfere recursos para que as secretarias estaduais de educação implementem o programa 
Ensino Médio Integral em Tempo Integral (Emiti). De acordo com informações do site oficial da Secretaria de Estado da Educação de Santa Catarina ${ }^{1}$, em 2017, 16 escolas da rede pública estadual, que atendiam aos critérios da referida portaria, adotaram o programa, e em 2019, o programa já conta com 31 escolas. A implementação do Emiti em Santa Catarina tem como parceiro o Instituto Ayrton Senna (IAS) e apoio do Instituto Natura, o que caracteriza uma parceria público-privada.

A parceria com o IAS representa a adoção de um modelo educacional que contempla uma proposta pedagógica, a adoção de um material didático, acompanhamento e formação de professores. A proposta do IAS tem como premissa a integração curricular. O currículo é dividido em Áreas de Conhecimento (Linguagens, Matemática, Ciências da Natureza e Ciências Humanas) e Núcleo Articulador (Estudos Orientados; Projeto de Intervenção e Pesquisa, Projeto de Vida). Atualmente, é uma das propostas ofertadas no Guia de Implementação do Novo Ensino Médio ${ }^{2}$ como itinerário formativo na Base Nacional Curricular Comum (BNCC).

Considerando a parceria já em execução e a proposta do Emiti, há questões que precisam de atenção, primeiramente a oferta de carga horária diária de 7 horas, tornando necessária a reorganização do quadro de professores e funcionários. Outro aspecto é a flexibilização e a integração curricular, além da introdução de componentes técnico-profissionais na matriz curricular do nível médio. Todas essas reestruturações têm efeito direto sobre as práticas curriculares, na medida em que cabe aos docentes e gestores a tarefa de atender aos novos objetivos e pressupostos metodológicos que tal política pública fomenta e, ao mesmo tempo, estar em consonância com o que preconiza o projeto proposto pelo IAS.

$\mathrm{O}$ foco da nossa discussão recai, sobretudo, sobre aspectos que dizem respeito às práticas curriculares dos professores, procurando entender de que forma elas são afetadas pela parceria firmada entre a Secretaria de Estado da Educação de Santa Catarina e o IAS, no que tange à adoção de uma proposta educacional advinda de uma instituição privada no contexto da educação pública. Dessa forma, o objetivo deste artigo consiste em discutir o lugar das práticas curriculares dos professores no Emiti, considerando a referida parceria.

Esta investigação também leva em conta as modificações sociais, políticas, econômicas e culturais pelas quais estamos passando, uma vez que somente assim é possível criticar as atuais políticas curriculares e sermos capazes de "dar respostas a essas modificações, empreender novas interpretações sobre as questões de nosso tempo" (LOPES, 2004, p. 110). 
Para isso, foi realizada uma pesquisa, de abordagem qualitativa, que, segundo André (2013), se fundamenta numa perspectiva em que o conhecimento é socialmente construído pelas pessoas, que transformam a realidade e ao mesmo tempo transformam a si mesmas. A investigação ocorreu em uma das escolas que implantou o programa do Emiti, numa cidade da região norte de Santa Catarina. Nessa escola, foram ouvidos quatro professores, por meio de entrevista semiestruturada, sobre diversos aspectos referentes às suas práticas curriculares. Após a transcrição das entrevistas, os dados foram analisados por intermédio de análise de conteúdo, que permite "conhecer os textos e as mensagens contidas, deixando-se invadir por impressões, representações, emoções, conhecimentos e expectativas" (FRANCO, 2012, p. 44).

Sintetizando, o presente artigo traz uma breve introdução, para apresentar a lei que implementa o Emiti, seus desdobramentos e implicações em relação à parceria com o IAS. Em seguida, foram trazidas questões referentes às políticas curriculares e à inserção da lógica privada sobre o setor público e como essa lógica chega até os professores participantes da pesquisa, trazendo a percepção desses professores acerca da aplicação da proposta do Instituto.

Considerando as falas dos referidos docentes, fez-se uma divisão em duas categorias para análise, sendo elas: infraestrutura necessária para a efetivação das práticas curriculares no Emiti; e práticas curriculares e a autonomia curricular no Emiti.

As considerações trazem algumas discussões que precisam ser retomadas diante do atual cenário nacional em relação ao avanço da lógica privada sobre a pública.

\section{Políticas curriculares e 0 avanço da lógica privada sobre o setor público}

Para refletir sobre as atuais políticas curriculares para o Ensino Médio, não podemos deixar de mencionar os desafios que se colocam a partir do caráter de padronização e de homogeneização advindo da proposta de um currículo nacional. De acordo com Apple (2011, p. 71), o currículo não é um conjunto neutro de conhecimentos, "ele é sempre parte de uma tradição seletiva, resultado da seleção de alguém, da visão de algum grupo acerca do que seja conhecimento legítimo". A questão é: Como unificar um currículo numa sociedade tão desigual? Considerando que vivemos numa época denominada por Apple (2011, p. 73) de "restauração conservadora", diante de uma proposta de currículo unificado, o princípio de educação pública e de currículo que atenda às culturas e histórias de toda a população pode estar ameaçado. 
O currículo nacional para a Educação Básica já é realidade em muitos países. Conforme Pacheco (2002, p. 88), estabelecer um currículo nacional faz parte de um "processo de construção da identidade coletiva", que pode servir para a regulação e a seleção de objetivos de aprendizagem e de organização do conhecimento oficial. Todavia, numa perspectiva conservadora, um currículo nacional poderá representar a criação de critérios de controle da aprendizagem dos alunos e das práticas docentes. Nesse cenário, encontram-se as recentes políticas curriculares no Brasil, e entre elas destacamos o Emiti, que, em Santa Catarina, está sendo implementado por meio de uma parceria público-privada. Esse tipo de parceria pode representar a perda da autonomia da rede pública de ensino e, como afirmam Comerlatto e Caetano (2013, p. 246), a "coisificação humana", atribuindo aos professores a tarefa de executar propostas previamente definidas pela lógica privada.

Para Lopes (2004, p. 111), uma política curricular é

[...] uma política de constituição do conhecimento escolar: um conhecimento construído simultaneamente para a escola (em ações externas à escola) e pela escola (em suas práticas institucionais cotidianas). Ao mesmo tempo, toda política curricular é uma política cultural, pois o currículo é fruto de uma seleção da cultura e é um campo conflituoso de produção de cultura, de embate entre sujeitos, concepções de conhecimento, formas de entender e construir o mundo.

Se partirmos do pressuposto de que a política curricular é um campo de disputas, de concepções de mundo, não podemos deixar de mencionar que é também um espaço público. Por essa razão, a escola também é um local de tomada de decisões, pois é lá que a política se consolida, o que exige o posicionamento dos professores, dos pais, dos alunos e de todos os demais profissionais que atuam nas escolas. Eles são produtores de discursos e dão significado a tudo o que acontece no âmbito escolar (PACHECO, 2000). De acordo com o documento da BNCC (BRASIL, 2018), a autonomia dos sistemas e das redes de ensino consiste em adequar as proposições da base nacional à realidade local, ao contexto e às características dos alunos. A nossa questão é: se o Instituto Ayrton Senna é parceiro na implementação do Emiti em Santa Catarina, qual será de fato a autonomia curricular dos professores e da escola? De que forma os contextos locais serão considerados no currículo?

Ao refletir sobre a autonomia das escolas e dos professores, Barroso (2013) diz que esse conceito pode ser visto de duas formas, a primeira por permitir ultrapassar a rigidez e o caráter homogêneo de oferta do currículo, "através do recurso à territorialização das políticas educativas, ao desenvolvimento de projetos educativos próprios, ao reforço da participação e à diversificação da oferta” (BARROSO, 2013, 
p. 48). Na segunda, a autonomia delegada pela introdução de características da oferta privada torna a escola e os professores reféns da regulação e da concorrência, gerando segmentação e segregação dos setores públicos.

Diante disso, a racionalidade de mercado é delineada pelos instrumentos de regulação: a escola, o currículo e a avaliação.

Desse modo, o mercado não dispensa o Estado, esperando que este se responsabilize pelos aspetos mais questionados do currículo - os conteúdos e a avaliação - e estabeleça os critérios para que a qualidade escolar seja determinada pelos pais, transformados em consumidores e clientes (PACHECO, 2002, p. 85).

Nessa perspectiva, a avaliação torna-se um instrumento fundamental no processo, como afiança Hypólito (2010, p. 1.339):

A introdução de sistemas de avaliação da educação e do desempenho docente é crucial para essa regulação por parte do Estado, que passa a controlar e a avaliar desde longe, por meio da contratação de terceiros para realizar a avaliação externa - considerada como prestação de contas à sociedade civil (accountability). Tais modelos gerenciais são baseados na qualidade e no mérito e os problemas da educação ficam reduzidos a problemas técnico-gerenciais.

Nesse cenário, a escola assume o lugar central, faz as escolhas, porém dá a contrapartida por meio das avaliações externas. Na realidade é isso o que ocorre com a BNCC; o Estado definiu o modelo, os itinerários formativos, as aprendizagens essenciais e cabe aos sistemas e às redes de ensino e às escolas operacionalizar, construir um currículo e reelaborar os projetos pedagógicos de modo que possam dar as respostas por intermédio das avaliações.

Ao analisar as parcerias estabelecidas entre o Estado e instituições privadas, de que autonomia estamos falando? Para Barroso (2013), há um impulso do setor público em estabelecer as parcerias, o que está acarretando mudanças na educação "sem que isso signifique forçosamente uma privatização global do sistema" (BARROSO, 2013, p. 52). No entendimento do autor, com a hibridização do público e do privado, observamos a diluição das fronteiras, a complexificação das relações. Portanto, ainda não há como classificar esse movimento, é necessário acompanhar e investigar. Além disso, ressaltamos um aspecto relevante defendido por Barroso (2013, p. 53):

No contexto atual da crise do Estado Providência (e do modelo social a que deu origem), torna-se necessário reforçar a dimensão pública da escola pública, o que obriga a reafirmar os seus valores fundadores perante a difusão transnacional de uma vulgata neoliberal, que vê no serviço público a origem de todos os males da educação e na sua privatização a única alternativa. 
Além dos aspectos relacionados às parcerias público-privadas, ressaltamos que os avanços da lógica privada na educação podem ocorrer de outras maneiras. Moreira e Ramos (2015), ao refletirem sobre as questões curriculares, chamam a atenção para a mercantilização da educação, quando empresas educacionais oferecem sistemas apostilados, plataforma digitais, sistemas avaliativos e muitos outros produtos. Muitos docentes já sentem os impactos dessas mudanças, que acarretam empobrecimento de suas práticas curriculares, pois os objetivos se direcionam apenas para o bom desempenho (dos alunos e dos professores) nas avaliações em larga escala. Isso está afetando as práticas curriculares dos docentes que atuam na educação básica.

Outro aspecto a ser observado é que o capital privado está cada vez mais presente por meio de education business na prestação de serviços educacionais, muitas vezes em nome do Estado. Ball (2014) ressalta que é cada vez mais frequente a criação de redes educacionais internacionais, com o objetivo de garantir o acesso em massa das crianças à educação básica, especialmente em países onde a população é de baixa renda. Para o autor, ainda não é possível ter noção dos impactos dessas redes de negócios para as políticas de educação. Nota-se que existe uma crescente desestatização e mercantilização da educação e que os bens públicos estão se convertendo em bens privados. As pesquisas vêm mostrando que as parcerias público-privadas trazem novas práticas, novos valores e novas sensibilidades para a educação (BALL, 2014).

De acordo com Peroni (2013), as parcerias público-privadas estão aliadas ao fortalecimento do terceiro setor, no qual "o privado acaba influenciando ou definindo o público, não mais apenas na agenda, mas na execução das políticas, definindo o conteúdo e a gestão da educação, com profundas consequências para a democratização da educação" (PERONI, 2013, p. 30).

Acrescenta-se a essa reflexão que o controle social e a valorização do coletivo na tomada de decisões, importantes num processo democrático, acabam cedendo espaço para instituições privadas e organismos internacionais na definição das políticas educacionais e na definição dos currículos (PERONI, 2013).

As implicações dessa agenda repercutem nas práticas curriculares dos professores e na formação das subjetividades dos estudantes da educação básica. 


\section{As práticas curriculares no Emiti e 0 avanço da lógica privada sobre 0 setor público: a percepção dos professores}

A presente pesquisa, cujo objetivo é discutir o lugar das práticas curriculares dos professores do programa Emiti, considerando a parceria da Secretaria de Educação do Estado de Santa Catarina com o IAS, foi realizada em uma das escolas que implantou o programa, numa cidade da região norte de Santa Catarina. Nessa escola, foram ouvidos quatro professores, por meio de entrevista semiestruturada, sobre aspectos referentes às suas práticas curriculares.

É necessário explicitar que, embora a instituição de ensino tenha implementado a carga horária de 7 horas diárias como parte do programa Emiti em 2017, os arranjos curriculares chamados itinerários formativos ainda não tinham sido colocados em prática no momento da pesquisa, o projeto estava na primeira fase de implementação e a BNCC ainda não estava em vigor. De acordo com os Cadernos de Sistematização do $\mathrm{IAS}^{3}$, o currículo do Emiti está dividido em duas grandes áreas: Área de Conhecimento, que contempla as Linguagens, Matemática, Ciências da Natureza e Ciências Humanas; e Núcleo Articulador, que envolve Estudos Orientados (EO); Projeto de Intervenção e Pesquisa (PIP) e Projeto de Vida (PV).

Os EOs são voltados para o estudo mais aprofundado de assuntos de interesse dos alunos, e o reforço dos conteúdos abordados nas disciplinas acontece com participação voluntária. O PIP visa engajar os estudantes em temas relevantes e encorajá-los a conduzir pesquisas científicas, expor os dados encontrados e relacioná-los com os aspectos significativos para eles e para a comunidade que circunda a escola. A participação nesse projeto é compulsória para os alunos da modalidade de Emiti. Além disso, os PIPs são divididos em duas fases: na primeira, os alunos, sob a supervisão de um professor designado para tal, conduzem a pesquisa sobre o tema selecionado; na segunda parte, os alunos entram em contato com a comunidade a fim de relacionar seus achados e as realidades que os cercam. Por fim, o PV consiste em uma reunião com um grupo reduzido de estudantes para falar de assuntos que os atinjam de alguma maneira, como problemas na família, projetos pessoais e profissionais (SED; IAS, 2017?).

Com base nos resultados das entrevistas feitas com os professores do Emiti, considerado o cenário descrito anteriormente, observaram-se duas categorias nas falas, são elas: infraestrutura necessária para a efetivação das práticas curriculares no Emiti; e práticas curriculares e a autonomia curricular no Emiti. 


\section{Infraestrutura necessária para a efetivação das práticas curriculares no Emiti}

Levando em conta a análise de dados da pesquisa, pode-se afirmar que existem dificuldades que não devem ser ignoradas quando da efetivação de um currículo oferecido em período integral de forma ampla, pois há que se considerar as condições materiais das escolas e suas realidades. Nesse foco, parece-nos evidente que o professor B, ao descrever sua percepção diante da obrigatoriedade do tempo integral, identifica uma das limitações em relação à implementação do referido currículo:

Às vezes, a gente tem alguns documentários que podem passar direto da internet, baixar lá e tal. Vamos assistir isso aqui e fazer uma baita de uma aula. Uma aula ampla, dinâmica, diferenciada, se tu tiveres ferramentas. Então a gente não tem. A parte estrutural das escolas, não é só da nossa, vamos dizer assim, a visão geral, é muito defasada.

Ao observar a fala do professor B, a possibilidade de trabalhar o conteúdo por meio da web é uma ótima oportunidade, porém as escolas não oferecem a infraestrutura necessária, limitando a ação docente e também a sua possibilidade de fazer escolhas para suas aulas.

O professor C percebe dificuldade semelhante, haja vista compreender que o tempo integral prevê atividades para além do espaço da sala de aula:

é mais a questão estrutural. A questão de você ter, de repente, uma quadra coberta, um ginásio, de ter uma internet que funcione [...] então, assim, o que a gente sente é essa questão da estrutura.

Da mesma forma, o professor A ratifica a percepção dos outros, quando afirma:

Dentro de um modelo desse, que é de pesquisa, se não tiver internet... essas novas escolas, que estão na manchete ali. Essas novas escolas já estão berrando. Como vocês trazem para nós um projeto que depende $80 \%$ de pesquisa e tem escola que não tem internet. E a gente está no segundo ano aqui. [...] É um problema maior esse de estrutura, de não ter o material que precisa para esse modelo. Não é pedagógico.

Com as dificuldades enfrentadas nas escolas, o professor se vê limitado pela regulação e com dificuldades de implantar o que está proposto nos materiais didáticos do Instituto. Essa percepção não é apenas em relação ao Emiti, mas ocorre em todas as ofertas curriculares de Ensino Médio, conforme a fala do professor 1:

"Olha, no Ensino Médio é assim. Em relação ao Estado, nós temos uma defasagem na parte estrutural. É o único problema tanto no regular, no integral: é a falta de estrutura”. 
Nas afirmações dos professores participantes desta pesquisa, está claro que a proposta do Instituto Ayrton Senna traz opções de pesquisa e de realização de projetos, porém a proposta pode não ter condições de viabilidade e isso limita a prática e a autonomia curricular do professor, impedindo outras escolhas e possibilidades. Para Lopes (2004), isso mostra que, se por um lado o currículo é o centro de uma reforma, nesse caso do Ensino Médio, por outro, as escolas ficam limitadas à sua capacidade, que muitas vezes não atende às mudanças propostas.

Para a implementação de uma política curricular e para que a autonomia curricular do professor possa ocorrer, Morgado (2003) diz que são necessárias algumas condições, entre as quais está o acesso a recursos necessários para a implantação das mudanças e condições que permitam a escola ser um espaço de decisão curricular, e não apenas de implementação.

\section{Práticas curriculares e a autonomia curricular no Emiti}

Em suas reflexões sobre as práticas curriculares, Sacristán (2017) ressalta que sempre que se tem uma política curricular há um conjunto de forças atuando na determinação do currículo materializado por meio dos conteúdos, das práticas pedagógicas e da avaliação. No caso da presente pesquisa, temos o Instituo Ayrton Senna, a Secretaria de Estado da Educação, a direção da escola e os professores; todos compõem essas forças. "O equilíbrio de forças resultante dá lugar a um peculiar grau de autonomia de cada um dos agentes na definição da prática” (SACRISTÁN, 2017, p. 100). Por essa razão,

[...] o currículo que se realiza por meio de uma prática pedagógica é o resultado de uma série de influências convergentes e sucessivas, coerentes e contraditórias, adquirindo, dessa forma, a característica de ser um objeto preparado num processo complexo, que se transforma e constrói nesse processo (SACRISTÁN, 2017, p. 100).

A percepção de professores do Emiti ratifica essas forças convergentes e contraditórias presentes num ensino público com uma lógica privada. A fala do professor B exemplifica tal lógica:

O Instituto Ayrton Senna, que elabora todos os cadernos, a parte pedagógica. Então vêm algumas coisas prontas, só que a gente tem essa abertura que a gente pode reelaborar as aulas dentro do assunto, não fugindo muito, e também incluindo alguma coisa que a gente acha pertinente tocar no assunto no primeiro e segundo ano, porque algumas coisas vêm meio fora, tanto no currículo do Estado quanto do Instituto também. 
Nessa fala, também há um aspecto contraditório, pois, ao mesmo tempo em que o professor B afirma que é possível "reelaborar as aulas", ele também relata que isso deve ser feito "dentro do assunto, não fugindo muito". Por meio dessa contradição nota-se que pode estar faltando clareza no tocante ao que representa a presença do IAS na escola, uma vez que o Instituto elabora todos os cadernos e define o papel do professor, implicando limitação da prática e da autonomia curricular docente. Dessa forma, o professor não é o protagonista da decisão curricular e acaba tornando-se um executor de tarefas.

Morgado (2003) define autonomia curricular como sendo a possibilidade de os professores tomarem decisões no âmbito do desenvolvimento curricular, tanto no que diz respeito à adaptação ao currículo prescrito quanto às necessidades de seus alunos e às especificidades do contexto no qual a escola está inserida. Isso ocorre numa perspectiva de territorialização das políticas educativas na escola. A autonomia curricular, tanto da escola como do professor, efetiva-se quando o currículo é considerado um projeto, com a possibilidade de construir intenções pensadas de forma colegiada. Esse processo é sempre permeado pelas tensões e contradições, necessárias e pertinentes (MORGADO, 2011).

Para o mesmo autor, decisões coletivas de o que, para quem, quando e como ensinar e avaliar são imprescindíveis. Com isso, é possível mobilizar os docentes em torno dos objetivos de cada área do saber, entendidos também como "capacidades, atitudes e competências a desenvolver pelos estudantes, bem como dos modelos metodológicos que devem presidir ao desenvolvimento dos processos de ensino-aprendizagem" (MORGADO, 2011, p. 397). Além desses aspectos, a participação dos professores na elaboração do projeto faz com que a escola se torne um local de reconstrução do currículo, e não apenas o de implementação de algo prescrito. Portanto, a implementação de um projeto como o do Instituto Ayrton Senna pode limitar a autonomia curricular, comprometendo a construção de um projeto educacional coletivo e democrático.

Para reforçar essa visão, há que se considerar também o relato do professor C:

A gente tem esse... essas OPAs [Orientações para Planos de Aula], que são as apostilas que vêm do Instituto que, como eu falei para ti, é o esqueleto, e aí a gente tem suporte dos livros didáticos que vêm, e aí a gente senta, conversa, internet. A gente procura amarrar de todos os lados para fazer esse planejamento, mas vem um suporte já, um esqueleto mais ou menos pronto do Instituto Ayrton Senna, e aí a gente vai inserindo outras atividades, vai enriquecendo com vídeos, com links, então você vai conseguindo fazer esse processo todo. É bem legal. 
Se considerarmos a realidade das escolas brasileiras e as condições de trabalho oferecidas aos professores, como baixos salários, carga horária excessiva, pouco acesso à formação continuada, é possível compreender a razão pela qual o professor $\mathrm{C}$ acha "bem legal" o movimento feito por ele e seus colegas, justamente pela possibilidade de um momento de diálogo e discussão de suas práticas em sala de aula. Esse mesmo sentimento é expressado pela professora D:

Então a gente sempre conversa para adaptar, e essa adaptação muitas vezes o professor não consegue, por isso as formações com o Instituto Ayrton Senna, para ensinar esse professor a adaptar.

O que pode passar despercebido para os professores é o que representa uma proposta advinda de uma instituição privada no contexto da educação pública. Os professores parecem aceitar a proposta da parceria, porém não compreendem que a lógica que a sustenta é a de uma formação com base em princípios conservadores, que valoriza a aplicação prática dos conhecimentos, de formação para o mercado de trabalho, pouco abertos para uma prática curricular que contemple o caráter público e democrático do currículo e da escola. Uma das principais implicações dessas parcerias consiste na redução da autonomia do professor,

[...] desde quando recebe o material pronto para utilizar em cada dia na sala de aula e tem um supervisor que verifica se está tudo certo até a lógica da premiação por desempenho, que estabelece valores como o da competitividade entre alunos, professores e escolas (PERONI, 2013, p. 27-28).

Para os professores da escola investigada, há autonomia na escolha de alguns projetos, como mencionado pela professora $\mathrm{D}$ :

Nós temos essa liberdade, também essa autonomia de "Ah, eu quero trabalhar isso. Isso é pertinente". Vamos supor, eu quero trabalhar a questão do meio ambiente e reciclagem. Posso trabalhar isso. Por mais que o caderno vá numa linha, eu posso trabalhar, adaptar ele dentro dessa linha.

Essa abertura para o trabalho com projetos é possível em decorrência da ampliação da carga horária no Emiti; os professores podem planejar e executar projetos que não estão previstos no material didático, ainda que eles devam estar relacionados ao conteúdo. Podemos considerar que há uma autonomia curricular controlada. Diante dessas possibilidades relatadas pelos professores, verifica-se que na implementação de uma política curricular, de acordo com Lopes (2004, p. 113), os professores "têm diferentes histórias, concepções pedagógicas e formas 
de organização, que produzem diferentes experiências e habilidades em responder, favoravelmente ou não, às mudanças curriculares, reinterpretando-as”.

Nas parcerias analisadas por Cormelatto e Caetano (2013, p. 248), referindo-se justamente ao Instituto Ayrton Senna, alguns aspectos da lógica dessas parcerias são apresentados: "como os programas do Instituto são prontos, padronizados, a função do professor fica restrita a um técnico atuando apenas como executor das decisões já estabelecidas". As autoras alertam, ainda, no mesmo estudo, que os "programas em larga escala são heterônomos e não possibilitam a participação dos reais interessados, a comunidade escolar" (CORMELATTO; CAETANO, 2013, p. 236). As autoras asseveram ainda que a ausência de participação dificulta o exercício da gestão democrática da educação, cujos princípios se pautam na autonomia, na participação e no diálogo.

Ao perceber que a proposta do Instituto traz uma realidade de outro estado, necessitando de adaptações para a sua execução em Santa Catarina, já é um indício de que há alguma resistência por parte dos professores dessa escola. Isso pode ser observado na afirmação da professora D:

o OPA, ele foi construído em cima de uma realidade de uma periferia no Rio de Janeiro, a escola Chico Anísio, então nós temos que adaptar a nossa vivência aqui em Santa Catarina.

Para a mesma professora, o material não atende às necessidades locais, pois ela observa no diálogo com os colegas do Emiti que as OPAs, por não atender à expectativa, necessitam de melhorias e adaptações. Essa prática curricular é necessária para que os estudantes tenham a garantia de acesso aos conhecimentos e de atribuição de sentidos às situações vivenciadas na escola (LEITE, 2012).

Ainda que se observe, com os resultados desta pesquisa, que as práticas curriculares são afetadas pelas parcerias público-privadas, no sentido de limitar a autonomia do professor por meio de roteiros preestabelecidos e pela falta de condições de infraestrutura, notamos o esforço dos professores em garantir o acesso dos estudantes aos conhecimentos historicamente construídos. Mesmo que o Emiti seja um projeto educacional operacionalizado numa parceria público-privada, com a oferta de materiais didáticos, orientações, formação de professores, o caráter humano não se perde, tendo em vista que os professores, em meio às contradições desse sistema, exercem movimentos que levam à adaptação e modificação do currículo prescrito. Assim, a proposta inicial não se efetiva na íntegra. 


\section{Considerações}

Em relação à discussão proposta pelo presente artigo, pode-se afirmar que a parceria do Instituto Ayrton Senna é uma realidade no estado de Santa Catarina, apesar da sua aplicação ser restrita às escolas do Emiti. Diante do cenário e do referido avanço da inciativa privada sobre a pública, há que se considerar que os professores participantes desta pesquisa se colocam de forma clara no que se refere às limitações da infraestrutura existente nas escolas nas quais atuam e às adaptações que são necessárias no âmbito da prática.

Esses docentes entendem que a proposta do Instituto pode ser inviabilizada em função das condições, por hora, existentes em seus locais de trabalho. Apresentam-se, assim, as implicações do que significa o não reconhecimento das territorialidades e das realidades locais, refletindo no cotidiano básico das escolas e dificultando as ações e as práticas pedagógicas. Para Morgado (2000, p. 71), "a territorialização, traduzida globalmente pela possibilidade de interpretar e adequar localmente as resoluções centrais, é a palavra chave de todo o processo".

Quanto às implicações do que representa uma proposta baseada na lógica privada, no que tange à restrição da autonomia do professor, surge um fato contraditório na fala dos participantes da pesquisa, pois eles afirmam que podem fazer adaptações e sugestões no material recebido do Instituto e consideram tal possibilidade muito boa, todavia, em vários momentos, percebe-se que as possibilidades se restringem à inclusão de itens no que já está proposto. A inserção das sugestões a que se referem os professores não está na base da proposta, mas sim na adaptação dentro de uma lógica que não privilegia ou não permite construir uma identificação entre professores, estudantes e gestores, os quais são os atores essenciais e realmente capazes de respeitar as subjetividades, conhecer as limitações e possibilidades de seus espaços de trabalho.

Assim, apresenta-se a necessidade urgente da exigência do respeito à autonomia e às decisões curriculares da comunidade escolar, por meio de trabalho coletivo, permitindo atender às diferenças culturais de cada região do país.

Diante das considerações aqui colocadas, reiteramos a ideia de que parcerias público-privadas, como a do Emiti em Santa Catarina, não podem perder de vista a defesa de uma escola pública, "de uma escola democrática e não segregativa, baseada na universalidade do acesso, na igualdade de oportunidades, na partilha de uma cultura comum e na continuidade dos percursos escolares" (BARROSO, 2013, p. 54). 


\section{Notas}

1 Disponível em: http://www.sed.sc.gov.br/. Acesso em: 10 jun. 2019.

2 Disponível em: novoensinomedio.mec.gov.br/\#!/guia. Acesso em: 10 jun. 2019.

3 Disponíveis no site da Secretaria de Estado de Educação: <sed.sc.gov.br/programas-e-projetos/27909-ensino-medio-em-tempo-integral>. Acesso em: 11 jul. 2019.

\section{Referências}

ANDRÉ, Marli. O que é um estudo de caso qualitativo em educação? Revista da Faeeba - Educação e Contemporaneidade, v. 22, n. 40, 2013.

APPLE, Michael W. A política do conhecimento oficial: faz sentido a idéia de um currículo nacional? Currículo, Cultura e Sociedade, v. 11, p. 59-91, 2011.

BALL, Stephen J. Educação Global S.A.: novas redes políticas e o imaginário neoliberal. Ponta Grossa: Editora UEPG, 2014.

BARROSO, João. Autonomia das escolas: entre público e privado. In: PERONI, Vera Maria Vidal (org.). Redefinições das fronteiras entre o público e o privado: implicações para a democratização da educação. Brasília: Liber Livro, 2013.

BRASIL. Lei n. ${ }^{\circ} 13.415$, de 16 de fevereiro de 2017. Política de fomento à implementação de escolas de ensino médio em tempo integral. Brasília, 2017.

BRASIL. Ministério da Educação. Base nacional comum curricular. Proposta preliminar. Terceira versão. Brasília, 2018.

BRASIL. Ministério da Educação. Portaria $n .^{\circ} 1.145$, de 10 de outubro de 2016. Institui o Programa de Fomento à Implementação de Escolas em Tempo Integral. Diário Oficial da União, Brasília, 11 out. 2016.

CORMELATTO, Luciani Paz; CAETANO. Maria Raquel. As parcerias público-privadas na educação brasileira e as decorrências na gestão da educação: o caso do Instituto Ayrton Senna (IAS). In: PERONI, Vera Maria Vidal (org.). Redefinições das fronteiras entre o público e o privado: implicações para a democratização da educação. Brasília: Liber Livro, 2013.

FRANCO, Maria Laura P. B. Análise de conteúdo. Brasília: Liber livro, 2012.

HYPÓLITO, Álvaro Moreira. Políticas curriculares, Estado e regulação. Educação \& Sociedade, v. 31 , n. 113 , p. $1.337-1.354,2010$.

LEITE, Carlinda. A articulação curricular como sentido orientador dos projetos curriculares. Educação Unisinos, v. 16, n. 1, p. 87-92, 2012.

LOPES, Alice Casimiro. Políticas curriculares: continuidade ou mudança de rumos? Revista Brasileira de Educação, n. 26, p. 109-118, maio/ago. 2004.

MOREIRA, Antônio Flávio B.; RAMOS, Rosane K. Currículo, internacionalização e cosmopolitismo. In: MORGADO, José Carlos et al. (org.). Currículo, internacionalização e cosmopolitismo: desafios contemporâneos em contextos luso-afro-brasileiros. Santo Tirso: De Facto, 2015. v. 1 , p. $25-38$. 
MORGADO, José Carlos. A (des) construção da autonomia curricular. Porto: Asa, 2000.

MORGADO, José Carlos. Projecto curricular e autonomia da escola: das intenções às práticas. Revista Brasileira de Política e Administração da Educação, v. 27, n. 3, 2011.

MORGADO, José Carlos. Projecto curricular e autonomia da escola: possibilidades e constrangimentos. Revista Galego-Portuguesa de Psicologia e Educação, v. 10, n. 8, ano 7, 2003.

PACHECO, José Augusto. A flexibilização das políticas curriculares. In: SEMINÁRIO O PAPEL DOS DIVERSOS ATORES EDUCATIVOS NA CONSTRUÇÃO DE UMA ESCOLA DEMOCRÁTICA. Guimarães: Centro de Formação Francisco de Holanda, 2000. p. 71-78.

PACHECO, José Augusto. Políticas curriculares. Porto: Porto, 2002.

PERONI, Vera Maria Vidal. A gestão democrática da educação em tempos de parceria entre o público e o privado. Pro-Posições, Campinas, v. 23, n. 2, p. 19-31, 2012.

PERONI, Vera Maria Vidal (org.). Redefinições das fronteiras entre o público e o privado: implicações para a democratização da educação. Brasília: Liber Livro, 2013.

SACRISTÁN, J. Gimeno. O currículo uma reflexão sobre a prática. Tradução de Ernani F. da Fonseca Rosa. 3. ed. Porto Alegre: Penso, 2017. 352 p.

SED - SECRETARIA DE ESTADO DA EDUCAÇÃO DE SANTA CATARINA; IAS - INSTITUTO AYRTON SENNA. 2 - Princípios de educação integral. S.d. Disponível em: http://www. sed.sc.gov.br/programas-e-projetos/27909-ensino-medio-em-tempo-integral. Acesso em: 11 jun. 2019. 